\title{
Hypoglycemic effect of white (Morus alba L.) and black (Morus nigra L.) mulberry fruits in diabetic rat
}

\author{
Hemdan Ibrahem Mahmoud a,*, Said Mnaa Gad ElRab b, \\ Ayman Fathey Khalil c and Samah Mohamed Ismael ${ }^{c}$ \\ a Agricultural Chemistry Department, Faculty of Agriculture, Minia University, 61517, Minia, Egypt \\ b Home Economics Department, Faculty of Specific Education, Menofia University, 23811, Ashmoon, Menofia, Egypt \\ c Home Economics Department, Faculty of Specific Education, Ain Shams University, 11566, Cairo, Egypt \\ *Corresponding author at: Agricultural Chemistry Department, Faculty of Agriculture, Minia University, 61517, Minia, Egypt. \\ Tel.: +2.011.51344411. Fax: +2.086.2362182. E-mail address: hemdanm@minia.edu.eg (H. I. Mahmoud).
}

\section{ARTICLE INFORMATION}

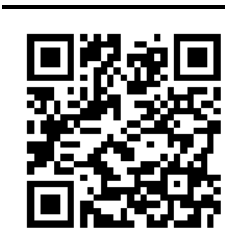

DOI: $10.5155 /$ eurjchem.5.1.65-72.903

Received: 11 August 2013

Received in revised form: 12 September 2013

Accepted: 15 September 2013

Online: 31 March 2014

\section{KEYWORDS}

\section{Alloxan}

Antidiabetic

Hypoglycemic

Morus alba fruits

Morus nigra fruits

Lipid peroxidation

\section{Introduction}

Diabetes mellitus (DM) is a worldwide disease affecting more than 347 million people [1]. In Egypt, it is estimated that 9 million people will become diabetic by the year 2025 [2]. DM refers to a disorder of metabolism of fat, carbohydrate and protein [3]. DM occurs due to lack of insulin secretion or its action on cells or both that leads to high blood glucose level [4]. Alloxan is widely used to induce diabetes mellitus in experimental animal models suggesting a close relation between hyperglycemia and diabetic complications and allowing investigation of hypoglycemic agents for the treatment of diabetes $[5,6]$. Moreover, DM is associated with increase production of reactive oxygen species and reduction of antioxidant defense system leading to oxidative stress, which plays an important role in tissue damage [5,7].

Nutrition is the major determinant for controlling DM, avoiding complications, successful aging and improving the quality of life [8]. Fruits and vegetables are the simplest form of healthful or functional foods [9]. Their physiologically active constituents are attenuate adverse effects associated with chronic diseases such as DM, cancer and cardiovascular Disease (CVD) $[10,11]$. Searching for new antidiabetic medicaments from natural sources is still attractive as most of these plant materials contain glycosides, alkaloids, terpenoids, flavonoids, cartenoids and other bioactive chemical components that are frequently implicated as having antidiabetic effect $[12,13]$.

White (Morus alba L.) and black (Morus nigra L.) mulberry belong to the family Moraceae. Mulberry fruits are widely known as a nutritious food, which can be eaten fresh, used in wine, juice and jam production or can be canned [14,15]. These berries are not only used as fruits, but also have been used effectively as natural medicines to cure sore throat, fever, hypertension and anemia [16,17]. Moreover, white mulberry fruits widely distributed in Egyptian agriculture are used to protect from liver and kidney damage, strengthen the joints, improve eyesight, and have anti-aging and radio protective effects $[15,18,19]$. In addition, recent studies have reported that 1-deoxynojirimycin in white mulberry has anti-diabetic effects and it reduces postprandial blood glucose levels through inhibition of $\alpha$-glucosidase and decrease of serum triglyceride levels $[20,21]$. The black mulberry fruit (M. nigra) is reported to possess antioxidant effect due to presence of phenolic compounds and anthocyanins [22]. Furthermore the antioxidant activity of three different extracts of $M$. nigra fruits on haemoglobin glycosylation, peroxidative damage to human 
erythrocytes, liver hepatocytes of rats and human low-density lipoprotein (LDL) showed that black mulberry fruits inhibit haemoglobin glycosylation induced by glucose to differing degrees [23]. Hansawasdi and Kawabata [24] reported that flavonoid extracted from $M$. indica has an antidiabetic activity in experimental animals. However, few reports have evaluated the antidiabetic and hypoglycemic effects of whole mulberry fruits as a dietary supplement in animal models. Thus, the present study aims to evaluate the effects of dietary intake of white (Morus alba L.) and black (Morus nigra L.) mulberry fruits either used individually or in combination on some biochemical and histopathological parameters in alloxaninduced diabetic rats.

\section{Experimental}

\subsection{Materials}

White and black mulberry fruits were purchased from the Egyptian local market. The fresh berries were dried at $70^{\circ} \mathrm{C}$ for 4 days and were grounded to measure their potential value and biological effects [25]. Chemicals were obtained from Sigma Chemical Co. (St. Louis, MO, USA).

\subsection{Methods}

\subsubsection{Determination of total phenolics, total flavonoid content and total antioxidant activity in mulberry fruits}

A 60 g portion of white and black mulberry fruits powder was extracted with $100 \mathrm{~mL}$ of methanol at room temperature for $5 \mathrm{~h}$. After filtration, the filtrate was washed with $50 \mathrm{ml}$ of methanol and the residue was extracted again. The extract was collected, and combined to determine the total antioxidant activity, total phenolics and total flavonoid content.

\subsubsection{Determination of total phenolics content}

The concentration of total phenolics content in mulberry fruits was measured by Follin-Ciocalteu colorimetric method [26]. Briefly, $0.5 \mathrm{~mL}$ of the methanolic extract solution $(5.0$ $\mathrm{mg} / \mathrm{mL}$ ) of mulberry fruits was mixed with $2.5 \mathrm{~mL} 10 \%$ FolinCioalteu's reagent $(v: v)$ and $2.0 \mathrm{~mL}$ of $7.5 \% \mathrm{Na}_{2} \mathrm{CO}_{3}$ was subsequently added. The reaction mixture was incubated at 45 ${ }^{\circ} \mathrm{C}$ for $40 \mathrm{~min}$, and the absorbance was measured at $765 \mathrm{~nm}$ against blank using spectrophotometer. Gallic acid was chosen as a standard, and the results were expressed as milligram of Gallic Acid Equivalents (GAE) per $100 \mathrm{~g}$ fresh matter of fruit (mg GAE/100 g fruit).

\subsubsection{Determination of total favonoid content}

The total flavonoid content of mulberry fruits was determined using the aluminum chloride colorimetric method described by Chang et al. [27]. Briefly, $0.5 \mathrm{~mL}$ of the methanolic extract solution $(1.0 \mathrm{mg} / \mathrm{mL})$ of mulberry fruits was mixed with $1.5 \mathrm{~mL}$ of $95 \%$ ethanol, $0.1 \mathrm{~mL}$ of $10 \%$ aluminum chloride $\left(\mathrm{AlCl}_{3}\right), 0.1 \mathrm{~mL}$ of $1 \mathrm{M}$ potassium acetate $\left(\mathrm{CH}_{3} \mathrm{COOK}\right)$, and 2.8 $\mathrm{mL}$ of distilled water. After incubation at room temperature for $40 \mathrm{~min}$, the reaction mixture absorbance was measured at 415 nm against blank. Quercetin was chosen as a standard. Using a seven point standard curve $(0-50 \mathrm{mg} / \mathrm{L})$, the levels of total flavonoid contents in mulberry fruits were determined. The data were expressed as milligram of qurcitin equivalents (QE) per $100 \mathrm{~g}$ fresh fruit (mg QE/100 $\mathrm{g}$ fruit).

\subsubsection{Determination of total antioxidant activity}

Total antioxidant activity in white and black mulberry fruits was determined following the method described by Jakobek et al. [28]. Briefly, $0.1 \mathrm{~mL}$ of methanolic solution containing 0.04 to $0.20 \mathrm{mg}$ of extract was mixed with $2 \mathrm{~mL}$ of distilled water and then $0.25 \mathrm{~mL}$ of $1 \mathrm{mM}$ methanolic solution of the 2,2-diphenyl-1-picrylhydrazyl (DPPH) radical was added. The mixture was vortexed thoroughly for $1 \mathrm{~min}$. Finally, the absorbance of the mixture was measured at $517 \mathrm{~nm}$ after standing at ambient temperature for $30 \mathrm{~min}$.

\subsubsection{Animals and Experimental design}

Thirty male Sprague-Dawley rats, weighing 160-200 g were purchased from Agricultural Research Center, Giza, Egypt. Upon arrival, the animals were given two weeks acclimation period, during which they were fed ad libitum a standard rat chow diet, with alternated $12 \mathrm{~h}$ dark/light cycle, and the ambient temperature was held between $21-25^{\circ} \mathrm{C}$. The care and use of laboratory animals were strictly in accordance with the guidelines prescribed by the University Ethical Committee.

In the current study diabetes was induced experimentally in fasted rats by intra-peritoneal injection of a single dose of $150 \mathrm{mg} / \mathrm{kg}$ BW alloxan monohydrate dissolved in distilled water [29]. Animals were given $10 \%$ glucose solution to drink instead of tap water for three days until sustained hyperglycemia was established. The diabetic state was assessed by measuring the fasting plasma glucose concentration $72 \mathrm{~h}$ after alloxan treatment. The rats with a fasting plasma glucose level above $200 \mathrm{mg} / \mathrm{dl}$ were selected for the experiment and considered as diabetics [30]. Treatment was started after 3 days of induction of alloxan and continued for 4 weeks. each):

Animals were divided into the following groups (6 rats

Group I: Normal control group was fed standard rat chow $\operatorname{diet}(\mathrm{NC})$.

Group II: Diabetic control group injected with alloxan and fed standard rat chow diet (DC).

Group III: Diabetic rats received daily powdered white mulberry fruit at 5\% level [31] mixed with the chow diet (D+WMF).

Group IV: Diabetic rats received daily powdered black mulberry fruit at $5 \%$ level mixed with the chow diet (D+BMF).

Group V: Diabetic rats received daily powdered of equal amounts of both white and black mulberry fruits at $5 \%$ level mixed with the chow diet (D+W and BMF).

\subsubsection{Blood Sampling}

Four weeks after mulberry fruits administration, food was withdrawn for 12 hours. The fasting animals were sacrificed and blood samples were collected into clean centrifuge tubes. The blood samples were allowed to coagulate and were centrifuged at $3000 \mathrm{rpm}$ for 20 minutes to separate the blood serum. Separated serum was stored at $-20{ }^{\circ} \mathrm{C}$ for subsequent biochemical analyses. Food consumption was monitored daily and body weight was determined once a week.

\subsubsection{Biochemical Analysis}

Fasting blood glucose was measured enzymatically and colorimetrically in serum immediately [32]. Triglycerides TG, total Cholesterol TC and High density lipoprotein cholesterol HDLc were colorimetrically determined in rat serum using enzymatic methods [33-35]. Low density lipoprotein cholesterol LDLc was calculated by using formula given by Friedewald et al. [36] (mg/dl) as follows;

LDLc $=$ TC - HDLc $-(\mathrm{TG} / 5)$

Liver function was determined by measuring the activities as aspartate aminotransferase (AST) and alanine aminotransferase (ALT) in serum using colorimetric method [37]. Blood urea nitrogen (BUN) was determined according to the methods of Fawcett [38]. 
Table 1. Total phenolic, total flavonoid content and total antioxidant activity of white and black mulberry fruits.

\begin{tabular}{|c|c|c|c|}
\hline Species & $\begin{array}{l}\text { Total phenolics } \\
\text { (mg GAE/ } 100 \mathrm{~g} \text { fresh mass) }\end{array}$ & $\begin{array}{l}\text { Total flavonoids } \\
\text { (mg QE/100 g fresh mass) }\end{array}$ & $\begin{array}{l}\text { Total antioxidant activity } \\
(\mu \mathrm{g} / \mathrm{mL})\end{array}$ \\
\hline$\overline{\text { Morus alba }}$ & 983 & 129 & 237 \\
\hline Morus nigra & 1366 & 256 & 178 \\
\hline
\end{tabular}

Table 2. Effects of white and black mulberry fruits on body weight and food efficiency ratio (FER) a.

\begin{tabular}{llll}
\hline Group & Initial weight (g) & Final weight (g) & FER (\%) \\
\hline Group I: NC & $180.2 \pm 3.42$ & $208.4 \pm 6.07$ & $4.96 \pm 0.22$ \\
Group II: DC & $174.0 \pm 3.19$ & $148.2 \pm 4.41 \mathrm{~b}$ & $-4.56 \pm 0.43 \mathrm{~b}$ \\
Group III: D+WMF & $175.6 \pm 3.39$ & $182.2 \pm 5.27 \mathrm{~b}, \mathrm{c}$ & $2.18 \pm 0.18 \mathrm{~b}, \mathrm{c}$ \\
Group IV: D+BMF & $173.4 \pm 4.09$ & $186.8 \pm 4.09 \mathrm{~b}, \mathrm{c}$ & $2.33 \pm 0.29 \mathrm{~b}, \mathrm{c}$ \\
Group V: D+W and BMF & $181.4 \pm 2.90$ & $198.6 \pm 5.38^{\mathrm{c}}$ & $2.78 \pm 0.15 \mathrm{~b}, \mathrm{c}$ \\
\hline
\end{tabular}

a The values are mean \pm SD of 6 rats in each group.

b Significantly different from normal control group at $p<0.05$.

c Significantly different from diabetic control group at $p<0.05$.

The determination of serum creatinine was performed according to Larsen [39]. Plasma lipid peroxide (Malondialdehyde) was determined according to Ohkawa et al. [40]. The activity of $\alpha$-amylase was determined according to Rinderknecht et al. [41]. All the kits used in biochemical analysis were purchased from Biodiagnostic, Egypt.

\subsubsection{Histopathological examination}

Autopsy samples from liver, kidney and pancreas were taken from the rats in different groups. Then, samples were fixed in $10 \%$ formol saline solution for twenty four hours. Washing was done in tap water then serial dilutions of absolute ethyl alcohol were used for dehydration. Specimens were cleared in xylene and embedded in paraffin at $56^{\circ} \mathrm{C}$ in a hot air oven for twenty four hours. Paraffin bees wax tissue blocks were prepared for sectioning at 4 microns thickness by slidge microtome. The obtained tissue sections were collected on glass slides, deparaffinized and stained by hematoxylin and eosin stain for histopathological examination through the light microscope [42].

\subsubsection{Statistical analysis}

Means of results were calculated among 6 replicates, with their Standard Deviations (SD) for each group. Analysis of variance was used to make statistical comparisons (ANOVA) with Dunnett's post hoc test. SPSS computer program [43] was used to calculate the significance between groups at the same experiment at $5 \%$ probabilities.

\section{Results and discussion}

\subsection{Total phenolics, total flavonoid content and total antioxidant activity of mulberry fruits}

Control hyperglycaemia is highly valuable, since botanicals are spending time and efforts to discover effective edible polyphenols and flavonoids. The current research is a trial in many to make benefit for diabetic patients. The amounts of total phenolic compounds, total flavonoids and total antioxidant activity of white and black mulberry fruits were shown in Table 1. The results have demonstrated that mulberry fruits are a rich source of phenolics, especially for $M$. nigra (1366 mg GAE/100 g), which showed higher value than M. alba (983 mg GAE/100 g). In the same trend, M. nigra fruit has high total flavonoid values (256 mg QE/100 g fresh mass) than $M$. alba fruit (129 mg QE/100 g fresh mass). Unexpected data proved that $M$. alba fruit has high levels of total antioxidant activity $(237 \mu \mathrm{g} / \mathrm{mL})$ than M. nigra fruit $(178 \mu \mathrm{g} / \mathrm{mL})$. Our results were in agreement with Kaewkaen et al. [25] and Butkhup et al. [44]. Ercisli and Orhan [45] found that the highest total phenolic and flavonoid contents were observed in black mulberry fruit when compared with the fruit of the white mulberry. The variation of phenolic compounds, total flavonoids and antioxidant capacity in mulberry fruits depends on many factors, such as degree of maturity at harvest, genetic differences, and environmental conditions during fruit development [46]. Many reports revealed that the physiological function of natural food could be related to the anti-oxidative capacity of its phenolic components.

\subsection{Changes in body weight and food consumption}

The final body weight showed significant increase from the initial body weight in all the groups except in the diabetic group, in which there was significant decrease in final body weight compared with the initial one (Table 2). The failure of diabetic rats to gain weight during the 4-week period corresponded with the hyperglycemia seen during this period. Rats of treated mulberry groups (III, IV and V) showed higher gain in weight as compared with those in the diabetic control group but less than those in the normal control group. In addition, significant increase revealed in food efficiency ratio (FER) for all groups (diabetic rats) fed on white and black mulberry as well as its mixture comparing to the diabetic control group. Our findings are, in fact, in a good agreement with that for Andallu and Varadacharyulu [47]. Another theory stated that alloxan decreases body weight due to depressed synthesis of DNA and RNA in the diabetic animals [48]. In the same while, increasing food consumption and decreasing body weight noticed in diabetic control rats are remarks for the polyphagic condition. Also, the loss of weight is probable due to the excessive break down of tissue proteins [49]. Mulberry fruit administration decreases food consumption and improves body weight in the same direction. Obviously, that is indicating control over the polyphagia and muscle wasting due to the hyperglycemic condition.

\subsection{Changes in fasting blood glucose}

Table 3 shows the changes in fasting blood glucose level over 4 weeks. Normal control rats did not show any significant variation in the blood glucose throughout the experimental period. Intra-peritoneal injection of alloxan led to over 3-fold elevation of blood glucose levels in all diabetic rats. Individual treatment of either $M$. alba or M. nigra fruits decreased the hyperglycemia significantly $(\mathrm{p}<0.05)$ by 47 and $45 \%$, respectively, as compared to the diabetic control group, although no one of the mulberries alone failed to restore the level of blood glucose to that of the normal control. On the other hand, the mixture of M. alba and M. nigra fruits decreased the diabetic blood glucose levels to almost catch the normal control level. The obtained data are in a parallel with that of Singab et al. [50] and Ma et al. [51]. Grover et al. [52] stated that mulberry exhibited a potent hypoglycemic activity in fasted and non-fasted streptozotocin diabetic mice. 
Table 3. Effects of white and black mulberry fruits on fasting blood glucose level a.

\begin{tabular}{|c|c|c|c|c|}
\hline \multirow[t]{3}{*}{ Group } & \multicolumn{4}{|c|}{ Fasting blood glucose level (mg/dl) } \\
\hline & \multirow[t]{2}{*}{ At the time of grouping } & \multicolumn{3}{|c|}{ Days of white and black mulberry or its mixture supplement } \\
\hline & & 0 & 14 & 28 \\
\hline $\mathrm{NC}$ & $87.6 \pm 2.15$ & $90.8 \pm 2.77$ & $87.4 \pm 3.06$ & $89.4 \pm 2.11$ \\
\hline DC & $84.9 \pm 2.69$ & $245.4 \pm 7.75$ b & $242.6 \pm 8.88 \mathrm{~b}$ & $244.7 \pm 7.28^{b}$ \\
\hline $\mathrm{D}+\mathrm{WMF}$ & $88.2 \pm 3.19$ & $239.2 \pm 6.61^{b}$ & $187.4 \pm 6.30 \mathrm{~b}, \mathrm{c}$ & $129.4 \pm 4.70 \mathrm{~b}, \mathrm{c}$ \\
\hline $\mathrm{D}+\mathrm{BMF}$ & $87.0 \pm 1.53$ & $238.7 \pm 8.61 b$ & $189.6 \pm 5.96 \mathrm{~b}, \mathrm{c}$ & $133.6 \pm 5.86 \mathrm{~b}, \mathrm{c}$ \\
\hline $\mathrm{D}+\mathrm{W}$ and $\mathrm{BMF}$ & $85.4 \pm 2.99$ & $246.5 \pm 5.95 b$ & $169.3 \pm 5.58 b, c$ & $101.3 \pm 2.98^{c}$ \\
\hline
\end{tabular}

a The values are mean \pm SD of 6 rats in each group.

b Significantly different from normal control group at $p<0.05$.

c Significantly different from diabetic control group at $p<0.05$.

Table 4. Effects of white and black mulberry fruits on serum AST, ALT, BUN and creatinine level a.

\begin{tabular}{|c|c|c|c|c|}
\hline \multirow[t]{2}{*}{ Group } & \multicolumn{2}{|c|}{ Liver dysfunction indices } & \multicolumn{2}{|c|}{ Kidney toxicity indices } \\
\hline & AST (IU/dl) & ALT (IU/dl) & BUN (mg/dl) & Creatinine (mg/dl) \\
\hline $\mathrm{NC}$ & $19.60 \pm 0.84$ & $9.50 \pm 0.27$ & $36.04 \pm 1.06$ & $1.08 \pm 0.06$ \\
\hline DC & $35.77 \pm 1.12^{b}$ & $33.75 \pm 0.75$ b & $62.06 \pm 2.28 b$ & $1.82 \pm 0.08 \mathrm{~b}$ \\
\hline $\mathrm{D}+\mathrm{WMF}$ & $31.00 \pm 1.09 b$ & $27.25 \pm 1.11 \mathrm{~b}, \mathrm{c}$ & $56.04 \pm 1.30 \mathrm{~b}, \mathrm{c}$ & $1.59 \pm 0.06 \mathrm{~b}, \mathrm{c}$ \\
\hline $\mathrm{D}+\mathrm{BMF}$ & $30.97 \pm 1.18^{b}$ & $26.75 \pm 1.07 \mathrm{~b}, \mathrm{c}$ & $57.56 \pm 1.76 \mathrm{b,c}$ & $1.63 \pm 0.03 \mathrm{~b}, \mathrm{c}$ \\
\hline $\mathrm{D}+\mathrm{W}$ and $\mathrm{BMF}$ & $21.17 \pm 0.78 \mathrm{c}$ & $13.50 \pm 0.95 \mathrm{c}$ & $39.13 \pm 1.18 \mathrm{c}$ & $1.17 \pm 0.06^{c}$ \\
\hline
\end{tabular}

a The values are mean \pm SD of 6 rats in each group.

b Significantly different from normal control group at $p<0.05$.

c Significantly different from diabetic control group at $p<0.05$.

Table 5. Effects of white and black mulberry fruits on serum TG, TC, HDLc and LDLc level a.

\begin{tabular}{lllll} 
Troup & TG $(\mathbf{m g} / \mathbf{d l})$ & TC $(\mathbf{m g} / \mathbf{d l})$ & HDLc (mg/d) & \\
\hline NC & $42.26 \pm 1.45$ & $97.64 \pm 3.09$ & $60.16 \pm 2.05$ & LDLc (mg/d) \\
DC & $66.42 \pm 2.03^{\mathrm{b}}$ & $131.57 \pm 4.27 \mathrm{~b}$ & $32.13 \pm 1.29 \mathrm{~b}$ & $29.02 \pm 0.93$ \\
D+WMF & $49.94 \pm 1.18 \mathrm{~b}, \mathrm{c}$ & $110.91 \pm 4.05 \mathrm{~b}, \mathrm{c}$ & $41.98 \pm 1.34 \mathrm{~b}, \mathrm{c}$ & $86.49 \pm 2.18 \mathrm{~b}$ \\
D+BMF & $51.30 \pm 1.23^{\mathrm{b}, \mathrm{c}}$ & $112.78 \pm 4.89 \mathrm{~b}, \mathrm{c}$ & $49.13 \pm 1.52 \mathrm{~b}, \mathrm{c}$ & $59.60 \pm 1.88 \mathrm{~b}, \mathrm{c}$ \\
D+W and BMF & $45.26 \pm 1.45^{\mathrm{c}}$ & $103.90 \pm 3.01 \mathrm{c}$ & $53.89 \pm 1.68 \mathrm{c}$ & $52.02 \pm 1.93 \mathrm{~b}, \mathrm{c}$ \\
\hline
\end{tabular}

$\frac{\mathrm{D}+\mathrm{W} \text { and } \mathrm{BMF}}{\text { a The values are mean } \pm \text { SD of } 6 \text { rats in each group. }}$

b Significantly different from normal control group at $p<0.05$.

c Significantly different from diabetic control group at $p<0.05$.

Fasting blood glucose concentrations at the initial and final stages confirm uncontrolled hyperglycemia in untreated diabetic rats, whereas white and black mulberry fruits treatment remarkably decreased blood glucose concentrations in diabetic rats. The effect of white and black mulberry fruits in controlling hyperglycemia could be explained as follow: (I) the $\mathrm{N}$-containing pseudo-sugar isolated form mulberry fruits which inhibit the functions of $\alpha$-glucosidase, $\alpha$-mannosidase and $\beta$ galactosidase, (II) fagomine which strengthens the glucose induced insulin secretion similar to the action of glibenclamide, a sulfonylurea drug which stimulates the secretion of endogenous insulin, and (III) increase in tissue uptake of glucose by both white and black mulberry fruits [53].

\subsection{Changes in serum liver-kidney dysfunction indices}

The efficacy of white and black mulberry fruit as well as its mixture on serum aspartate aminotransferase (AST), alanine aminotransferase (ALT), blood urea nitrogen (BUN) and creatinine is shown in Table 4. These parameters were significantly $(\mathrm{p}<0.05)$ altered in alloxan induced diabetes comparing to normal control rats. In diabetic rats, administration of either white or black mulberry fruits individually led to non-significant $(p<0.05)$ decrease in AST, ALT, BUN and creatinine level comparing to diabetic control rats. On the other hand, administration a mixture of white and black mulberry fruits significantly $(\mathrm{p}<0.05)$ reduced AST, ALT, BUN and creatinine level by $40,60,37$ and $36 \%$, respectively, compared with the diabetic control rats. In the current study, increased the liver function activities of AST and ALT were observed in the diabetic animals. These results are in agreement with the results published by Zhang et al. [54]. It has already been demonstrated that tissue antioxidant status is an important factor in the development of diabetic complications [55]. The increase in the level of these enzymes in diabetes may be as a result of its leakage from the tissues and migration into the bloodstream as a result of alloxan acute toxicity which leads to the liver damage [56]. Furthermore, treatment with a mixture of white and black mulberry fruits produce a marked significant decrease of the elevated AST and ALT activities. Chaurasia et al. [57] attributed this decrease to the good hepato-protective and antioxidant activity of mulberry fruits which due to the presence of a number of constituents, such as flavonoids, anthocyanins, carotenoids and tannins. Since antioxidants are known to reduce the development of chemically induced liver damage [58]. In the same trend, Jarald et al. [59] showed that diabetic rats had a significant increase in creatinine and BUN levels as compared to the normal animals. Kidney dysfunctions in the diabetic rats may be related to the generation of reactive oxygen species and lipid peroxidation which are associated with tissue injury. The diabetic rats had higher values of plasma BUN than control rats [60]. In addition, Shah et al. [61] reported that increased oxidative stress and reduce antioxidative ability in diabetes results in renal tubular injury, proteinuria and leads to gradual loss of renal function.

\subsection{Changes in serum TG, TC, HDLc and LDLc level}

Data in Table 5 revealed that diabetic control group showed a significant $(p<0.05)$ increase in the values of TG, TC and LDLc and decrease in HDLc when compared with normal control. Either white or black mulberry treated groups (III and IV) showed a significant decrease in TC, TG and LDLc and a significant increase in HDLc compared with diabetic control. The best reduction in lipids profile was recorded for the combination between white and black mulberry supplement; the levels of triglycerides, total cholesterol, and LDLc were decreased by $31.8,22.9$, and $52.3 \%$, respectively, compared with diabetic control. On the other hand, administration of a mixture of white and black mulberry fruits caused a significant increase $(\mathrm{p}<0.05)$ in the HDLc level by $40.3 \%$ when compared with diabetic control. 
Table 6. Effects of white and black mulberry fruits on plasma $\alpha$-amalyse activity and lipid peroxide (MDA) a

\begin{tabular}{lll}
\hline Group & Plasma $\boldsymbol{\alpha}$-amalyse activity (U/L) & MDA (nmol/mL) \\
NC & $51.42 \pm 1.80$ & $3.21 \pm 0.13$ \\
DC & $206.22 \pm 8.30 \mathrm{~b}$ & $6.46 \pm 0.22 \mathrm{~b}$ \\
D+WMF & $97.78 \pm 3.19 \mathrm{~b}, \mathrm{c}$ & $4.58 \pm 0.18 \mathrm{~b}, \mathrm{c}$ \\
D $+\mathrm{BMF}$ & $90.44 \pm 3.09 \mathrm{~b}, \mathrm{c}$ & $4.70 \pm 0.15 \mathrm{~b}, \mathrm{c}$ \\
D+W and BMF & $63.22 \pm 1.90 \mathrm{c}$ & $3.93 \pm 0.19 \mathrm{c}$ \\
\hline
\end{tabular}

a The values are mean \pm SD of 6 rats in each group.

b Significantly different from normal control group at $p<0.05$.

c Significantly different from diabetic control group at $p<0.05$.

Supporting to our findings, Andallu and Varadacharyulu [47] found $16 \%$ decrease in triglycerides in type 2 diabetic patients after treatment with mulberry powder-filled capsules. They also reported that cholesterol, LDL cholesterol, and vLDL cholesterol were reduced by 12,23 , and $17 \%$, respectively, in type 2 diabetic patients after treatment with mulberry powder. Diabetes mellitus is also strictly related to other metabolic disorders, in which the most important one is lipid abnormalities, characterized mainly by high triglyceride, cholesterol, LDL-cholesterol and low HDL-cholesterol levels [62], which were also observed in our alloxan-induced diabetic control rats. Increased levels of triglycerides are a risk factor for atherosclerotic coronary disease. LDL and vLDL carry cholesterol to the peripheral tissues where it is deposited; hence, high levels of LDL and vLDL are atherogenic. HDL transports cholesterol from peripheral tissues to the liver and thus aids in its excretion (protective effect). Consumption of plant material like mulberry fruits, containing antioxidants, carotenoids, polyphenol and phytonutrients increases the antioxidant status in blood and tissues, as these compounds are capable of modulating LDL oxidation through several mechanisms [63]. At the same time, mulberry fruit might also be influencing lipoprotein associated cholesterol fractions and probably the phytocomponents exert action similar to the drugs lovastatin and simvastatin that are used for controlling the imbalance in plasma lipoprotein in diabetes.

\subsection{Changes in $\alpha$-amylase activity and lipid peroxidation (MDA)}

Compared the normal control group with its counterpart the diabetic control group, a significant increase in terms of plasma $\alpha$-amylase activity reached up to $301 \%$ (Table 6). The findings of the present study showed that the administration of white and black mulberry fruits or its combination to surviving diabetic rats significantly reduced $\alpha$-amylase activity, which plays a key role in the digestion of carbohydrates. A significant increase in plasma lipid peroxide (MDA) levels (101\%) was observed in the diabetic control group compared to the normal control. Diet supplemented with white and black mulberry fruits either individually or in combination induced a significant decrease of MDA levels in plasma compared to the diabetic control group (Table 6). $\alpha$-Amylase is the main enzyme in humans responsible for the breakdown of starch into simple sugars (dextrin, maltotriose, maltose and glucose). $\alpha$-amylase is well known enzyme in the management of hyperglycemia linked to type 2 diabetes. $\alpha$-amylase inhibitors have been thought to improve glucose tolerance in diabetic patients [64]. In the current study, administration of white and black mulberry or its combination to diabetic rats significantly reduced $\alpha$-amylase activity. This was indicative of lowered levels of absorbable glucose being formed from the digestion of carbohydrate and leading to reduced levels of blood glucose. The inhibition of $\alpha$-amylase activity in the human digestive tract represents one of the therapeutic approaches commonly used for the control and prevention of postprandial hyperglycemia in non-insulin-dependent diabetic patients through reducing the uptake of glucose released by those enzymes from starch [65]. Oxidation remark in our experiment was parallel to the data of Ma et al. [48] which reported that $M$. alba flavonoids reduced the hepatic MDA level in model group compared with streptozotocin-diabetic rats. Lipid peroxidation is a marker of cellular oxidative damage initiated by reactive oxygen species $[66,67]$. It was reported that diabetics are highly sensitive to oxidative stress [68]. In alloxan-diabetic animals, the alloxan generates nitric oxide, which is a powerful free radical oxidant results in an increase in serum level of lipid peroxides due to oxidation of cells [48]. In our experiment, administration of $M$. alba or M. nigra suppresses the elevation of lipid peroxides in alloxan-diabetic rats compared with diabetic control rats. The data included in this work suggested that mulberry fruits prevents cellular damage induced by alloxan via inhibition of lipid peroxidation possibly through antioxidant mechanisms due to its high flavonoids content, which is in accordance with the reported data on this kind of compounds [69], as well as it preserves the capability of insulin secretion. Also, this finding is in agreement with those of Coskun et al. [70], who reported that a natural antioxidant quercetin has a protective effect in diabetes by decreasing the oxidative stress and preservation of pancreatic cell integrity.

\subsection{Histopathological investigations}

The normal liver tissue showed no histopathological finding with normal histological structure of the central vein and surrounding hepatocytes, where the liver tissue of diabetic rat showed ballooning degeneration in hepatocytes associated with dilation in the central vein (Figure $1 \mathrm{~A}$ and $\mathrm{B}$ ). The white mulberry fruit administration brought back the cellular arrangement around the central vein and only mild congestion was noticed in the central veins (Figure 1C). Treating diabetic rats with black mulberry or with the mixture of white and black mulberry did not show any significant change of liver histology (Figure 1D and E). At the same time, kidney sections of alloxandiabetic rat showed congestion in the glomerular tuft associated with degeneration in the tubular lining epithelial cells of the cortex (Figure 2B) comparing with normal histological structure of the glomeruli and tubules at the cortex in the kidney of normal control rat (Figure 2A). Kidney of white mulberry fruit treated diabetic rat showed swelling degeneration in the lining epithelial cells of the cortical tubules (Figure 2C). Microscopic examination of the kidney of the treated diabetic rats with black mulberry fruit showed degeneration in the lining tubular epithelial cells in the cortical portion (Figure 2D), while an improvement in kidney structure of diabetic rat administrated with mixture of white and black mulberry fruits occurred and only mild congestion was noticed in the cortical blood vessels (Figure 2E). In general, berries are able to facilitate a very strong drug for diabetic rats as has been shown from the physiological histogram sections in different organs. Liver section results run parallel to the study of Ma et al. [51] which indicated that rats treated with 100 or 200 $\mathrm{mg} / \mathrm{kg}$ mulberry flavonoid showed considerably lower hepatic lipid accumulation and more liver injury recovery than those of the untreated diabetic rats.

The light microscropic examination by specific staining of pancreas in normal tissues section shows normal histological structure of the island of Langerhans cells as endocrine and the acini as excocrine (Figure 3A). 

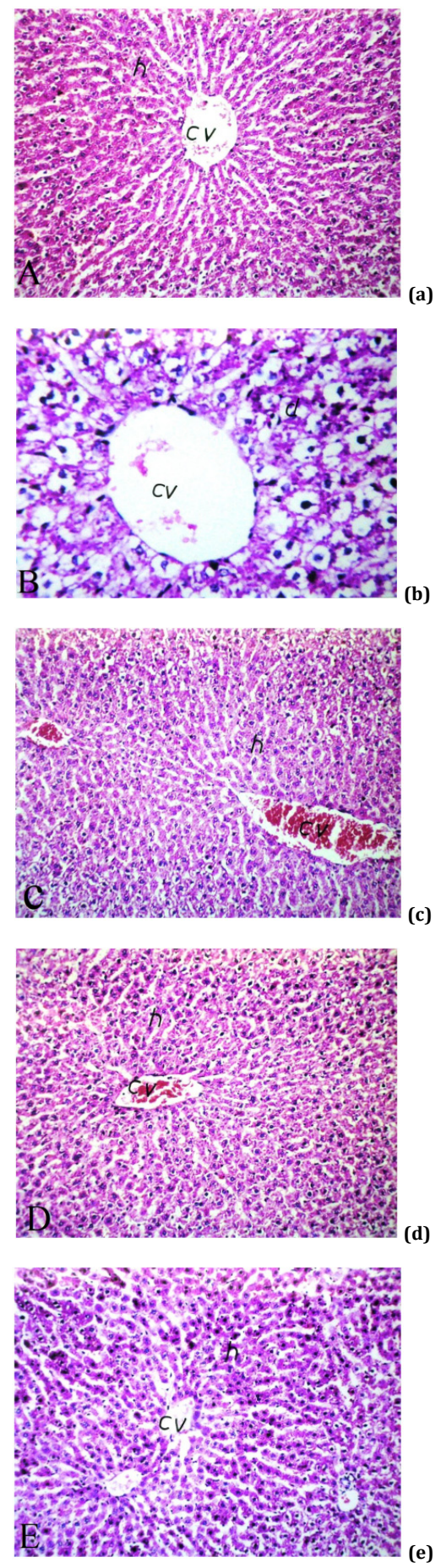

Figure 1. Liver histological structure of rats in normal control group (A), untreated diabetic control group (B), diabetic rats treated with white mulberry fruits (C), black mulberry fruits (D) and mixture of white and black mulberry fruits (E) (HX+EY164). [CV; central vein - h; surrounding hepatocytes $-d$; degenerated hepatocytes].

The alloxan diabetic rats showed atrophy in the island of Langerhans cells, associated with focal haemorrhage in between the acini and lobules (Figure 3B). However, treatment of alloxan-diabetic rats with either white and black mulberry or its mixture made recovery in the pancreas structure and only atrophy was noticed in the island of langerhans cells (Figure 3C, D and E). In the histogram sections for berries, there was a good correlation between potent valuable compounds and antioxidant activity with improvements for histopathological organ sections. At the same time, this study correlate with the reports of Mohammadi and Naik [71], who stated that the histopathologic studies undertaken on the islets demonstrated the recovery of damaged islets and an improvement in the number of B cells after treatment with M. alba extract.
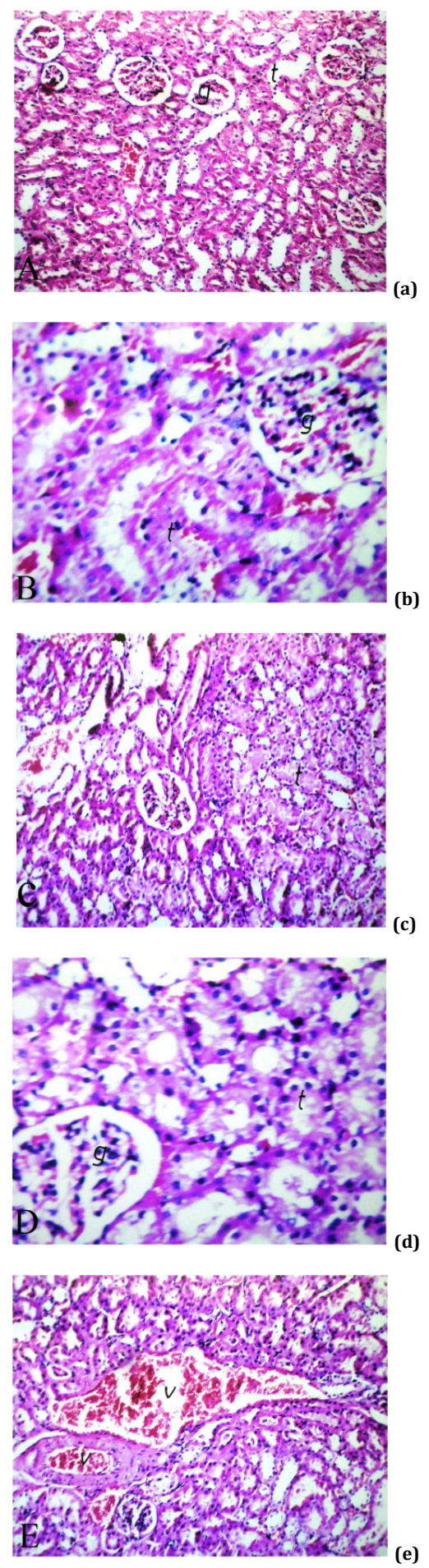

Figure 2. Histological examinations of kidney tissues of rats in normal control group (A), untreated diabetic control group (B), diabetic rats treated with white mulberry fruits group (C), black mulberry fruits group (D) and mixture of white and black mulberry fruits group (E) (HX+EY160). [g; glomeruli - t; surrounding cortex tubules - v; cortical blood vessels congestion]. 

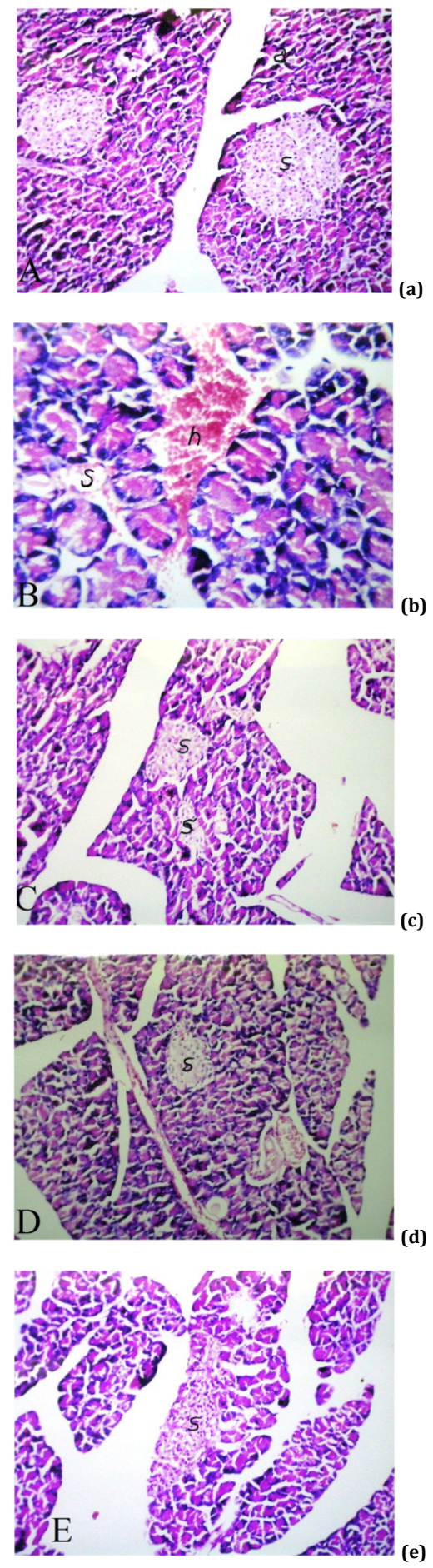

Figure 3. A photomicrograph of the pancreas of rats in normal control group (A), untreated diabetic control group (B), diabetic rats treated with white mulberry fruits group (C), black mulberry fruits group (D) and mixture of white and black mulberry fruits group (E) (HX+EY160). [s; endocrine Langerhans cells - a; exocrine acini - $h$; focal haemorrhage].

The regenerative effect of the pancreatic cells by white and black mulberry fruits or its mixture via exocrine cells of pancreas may enlighten the positive effects of these fruits on the production of insulin.

\section{Conclusion}

In conclusion, our study revealed that white and black mulberry fruits either used individually or in combination have pronounced antidiabetic and hypoglycemic effects in rats. The efficacy of these fruits was expressed by lowered blood glucose level, improvement of lipid profile and inhibition of lipid peroxidation and $\alpha$-amylase activity. In addition, our results were further confirmed with histopathological examination of liver, kidney and pancreas showed normal histoarchitecture. In general a combination of the white and black mulberry fruits is more effective than individual supplement in the treatment of diabetic rats for synergistic and ameliorating effects attributed to the high content of phenolics and flavonoids that possess antioxidant activity.

\section{Acknowledgement}

Deep thanks are due to Prof. Adel Khlosy, Pathology Department, Faculty of Veterinary Medicine, Cairo University, Egypt for his great assistance in histopathological examinations.

\section{References}

[1]. Danaei, G.; Finucane, M. M.; Lu, Y.; Singh, G. M.; Cowan, M. J.; Paciorek, C. J. Lin, J. K. Farzadfar, F.; Khang, Y. H.; Stevens, G. A.; Rao, M.; Ali, M. K.; Riley, L. M.; Robinson, C. A.; Ezzati, M. Lancet 2011, 378, 31-40.

[2]. Herman, W. H.; Aubert, R. E.; Ali, M. A.; Sous, E. S.; Badran, A. East Mediterr. Health. J. 1997, 3, 144-148.

[3]. Bliss, M. The Discovery of Insulin. University of Chicago Press, Chicago, USA, 2000.

[4]. Gillies, C. L.; Abrams, K. R.; Lambert, P. C.; Cooper, N. J.; Sutton, A. J.; Hsu, R. T. BMJ 2007, 334(7588), 299-307.

[5]. Rabbani, S. I.; Devi, K.; Khanam, S. Indian J. Exp. Biol. 2009, 47, 804810.

[6]. Kar, A. B; Chaudhry, K.; Bandyopadhyay, N. C. J Ethnopharmacol. 2003, 24, 105-108.

[7]. Jayakar, B.; Rajkapoor, S. B. J. Herb. Pharmacother. 2004, 4(1), 35-40.

[8]. Schiller, J. S.; Bernadel, L. Vital Health Stat. 2004, 3, 10-48.

[9]. Hasler, C. M.; Bloch, A. S.; Thomson, C. A.; Enrione, E.; Manning, C. J. Am. Diet. Assoc. 2004, 104(5), 814-826.

[10]. Millen, B. E.; Quatromoni, P. A.; Pencia, M.; Kimokoti, R.; Mam, B. Cobain, S. et al. J. Am. Diet. Assoc. 2005, 105, 1732-1734.

[11]. Bazanno, L. A.; He, J.; Ogden, L. G.; Loria, C. M.; Vupputuri. S.; Myers, L.; Whelton, P. K. Am. J. Clin. Nutr. 2002, 76, 93-99.

[12]. Abd EI-Ghany, M. A. Egypt. J. Nutr. 2002, 17(3), 227-244.

[13]. Huang, T. H.; Kota, B. P.; Razmovski, V.; Roufogalis, B. D. Basic Clin Pharmacol. Toxicol. 2005, 96, 3-14.

[14]. Ning, D. W.; Lu, B.; Zhang, Y. L. China Fruit Veg. Proc. 2005, 5, 38-40.

[15]. Wattanathorn, J.; Muchimapura, S.; Thukhammee, W.; Tong-un, T.; Wannanon, P.; Nattaporn, P Pratchaya, K.; Thanes, C.; Wiroje, K.; Suttisan P.; Sathaporn, W. Am. J. Applied Sci. 2012, 9, 1503-1511.

[16]. Ma, Y. P. Xinjiang J. Trad. Chin. Med. 2002, 20, 83-84.

[17]. Gong, S. X.; Zhu, J. P. J. Zhejiang Univ. Trad. Chin. Med. 2008, 32, 350352.

[18]. Shizhen, L. Compendium of Materia Medica. $1^{\text {st }}$ ed. Foreign Language Press, ISBN-10, 7119032607, 2008.

[19]. Hamzaa, R. G.; El Shahat A. N.; Mekawey, H. M. S. Biochem. Anal Biochem. 2012, 1(122), 1-8, doi:10. 4172/2161-1009. 1000122

[20]. Kojima, Y.; Kimura, T.; Nakagawa, K.; Asai, A.; Hasumi, K.; Oikawa, S. Miyazawa, T. J. Clin. Biochem. Nutr. 2010, 47, 155-161.

[21]. Kwon, H. J.; Chung, J. Y.; Kim, J. Y.; Kwon, O. J. Agric. Food Chem. 2011, 59, 3014-3019.

[22]. Kostic, D. A.; Dimitrijevic, D. S.; Mitic, S. S.; Mitic, M. N. , Stojanovic, G. S.; Zivanovic, A. V. Trop. J. Pharm. Res. 2013, 12(1), 105-110.

[23]. Naderi, G. A.; Asgary, S.; Sarraf-Zadegan, N.; Oroojy, H.; Afshin-Nia, F. Phytother. Res. 2004, 18, 365-369.

[24]. Hansawasdi, C.; Kawabata, J. Fitoterapia 2006, 77, 568-573.

[25]. Kaewkaen, P.; Tong-Un, T.; Wattanathorn, J.; Muchimapura, S.; Kaewrueng, W.; Wongcharoenwanakit, S. Am. J. Agric. Biol. Sci. 2012, 7 (3), 322-329.

[26]. Tsantili, E.; Shin, Y.; Nock, J. F.; Watkins, C. B. Postharvest Biol. Tec. 2010, 57, 27-34.

[27]. Chang, C. C.; Yang, M. H.; Wen, H. M.; Chern, J. C. J. Food Drug Anal 2002, 10, 178-182.

[28]. Jakobek, L.; Seruga, M.; Medvidovic-Kosanovi, M.; Novak, I. Agric Conspec. Sci. 2007, 72(4), 301-306.

[29]. Sheweita, A. A.; Newairy, H. A.; Mansour, M. I. Toxicology 2002, 174, 131-139. 
[30]. Zhang, J.; Huang, Y.; Hou, T.; Wang, Y. Swiss Med. Wkly. 2006, 136, 529532.

[31]. Yang, X.; Yang, L.; Zheng, H. Food Chem. Toxicol. 2010, 48(8-9), 23742379.

[32]. Trinder, P. Ann. Clin. Biochem. 1969, 6, 24-27.

[33]. Fossati, P.; Prencipe, L. Clin. Chem. 1982, 28, 2077-2080.

[34]. Richmond, W. Clin. Chem. 1973, 19, 1350-1356.

[35]. Lopes-Virella, M. F.; Stone, P.; Ellis, S.; Colwell, J. A. Clin. Chem. 1977, 23, 882-884.

[36]. Friedewald, W.; Levy, R.; Fredrickson, D. Clin. Chem. 1972, 18, 499 502.

[37]. Reitman, S.; Frankel, S. Am. J. Clin. Path. 1957, 28, 56-63.

[38]. Fawcett, J. K.; Scott, J. E. J. Clin. Path. 1960, 13, 156-159.

[39]. Larsen, K. Clin. Chim. Acta 1972, 41, 209-217.

[40]. Ohkawa, H.; Ohishi, W.; Yagi, K. Anal. Biochem. 1979, 95(2), 351-358.

[41]. Rinderknecht, H.; Wilding, P.; Haverback, B. J. Experientia 1967, 23(10), 805-805.

[42]. Banchroft, J.; Stevens, A.; Turner, D. Theory and practice of histological techniques. $4^{\text {th }}$ ed. Churchil Livingstone, New York, London, San Francisco, Tokyo, 1996.

[43]. SPSS. Statistical Package for Social Science. Computer Software, Ver. 10. SPSS Company: London, UK, 1998.

[44]. Butkhup, L.; Samappito, W.; Samappito, S. Int. J. Food Sci. Tech. 2013, 48(5), 934-940.

[45]. Ercisli, S.; Orhan, E. Food Chem. 2007, 103(4), 1380-1384.

[46]. Zadernowski, R.; Naczk, M.; Nesterowicz, J. J. Agric. Food Chem. 2005, 53 (6), 2118-2124.

[47]. Andallu, B.; Varadacharyulu, N. C. Clin. Chim. Acta 2003, 338, 3-10.

[48]. Szkudelski, T. Physiol. Res. 2001, 50 (6), 537-546.

[49]. Chatterjea, M. N.; Shinde, R. Text book of medical biochemistry. $5^{\text {th }}$ ed. New Delhi, Jaypee Brothers, Medical Publishers (P) Ltd., 2002.

[50]. Singab, A. N.; El-Beshbishy, H. A.; Yonekawa, M.; Nomura, T.; Fukai, T. J. Ethnopharmacol. 2005, 100, 333-338.

[51]. Ma, D. Q.; Jiang, Z. J.; Xu, S. Q.; Yu, X.; Hu, X. M.; Pan, H. Y. Chinese Herb. Med. 2012, 4(4), 314-318.

[52]. Grover, J. K.; Yadav, S.; Vats, V. J. Ethnopharmacol. 2002, 81(1), 81100.

[53]. Chen, F. J.; Nakashima, N.; Kimura, M. Yakugaku Zasshi. 1995, 115, 476-482.

[54]. Zhang, X. M.; Liang, W. B.; Mao, Y. Q.; Li, H.; Yang, Y.; Tan, H. R. Biomed. Pharmacother. 2009, 63, 180-186.

[55]. Wohaieb, S. A.; Godin D. Y. Diabetes 1987, 3, 1014-1021

[56]. Chaudary, A. R.; Alam, M.; Ahmad, M. Fitoterapia 1993, 64, 510-515.

[57]. Chaurasia, S.; Saxena, R. C.; Chaurasia, I. D.; Shrivastava, R. Int. J. Chem. Sci. 2011, 9(2), 489-492.

[58]. Hui-Yin, C.; Gow-Chin, Y. Food Chem. 2007, 101, 686-694.

[59]. Jarald, E. E. Joshi, S. B.; Jain, D. C. Indian J. Exp. Biol. 2008, 46, 660-667.

[60]. Shou-Chieh, W.; Shiow-Fen, L.; Chau-Jong, W.; Chao-Hsin, L.; WenChin, L.; Huei-Jane, L. eCAM. 2009, 4, 1-9.

[61]. Shah, S. V.; Baliga, R.; Rajapurkar, M.; Fonseca, V. A. J. Am. Soc. Nephrol. 2007, 18, 16-28.

[62]. Jain, S.; Bhatia, G.; Barik, R.; Kumar, P.; Jain, A.; Dixit, V. K. J. Ethnopharmacol. 2010, 127, 325-328.

[63]. Andallu, B.; Vinay Kumar, A. V.; Varadacharyulu, N. C. Int. J. Diabetes Dev. Ctries. 2009, 29(3), 123-128.

[64]. Lebovit, H. Diabetes Rev. 1998, 6, 132-145.

[65]. McDougall, G. J.; Stewart, D. Biofactors 2005, 23(4), 189-195.

[66]. Farber, J. L.; Kyle, M. E.; Coleman, J. B. Lab. Invest. 1990, 62, 670-679.

[67]. Hamzaa, R. G.; Mekawey, H. M. S.; El Shahat, A. N. Arab J. Nucl. Sci. Appl. 2013, 46 (2), 347-355.

[68]. Baynes, J. W. Diabetes 1991, 40, 405-412.

[69]. Oh, H.; Ko, E. K.; Jun, J. Y.; Oh, M. H.; Park, S. U.; Kang, K. H.; Lee, H. S.; Kim, Y. C. Plant Med. 2002, 68, 932-934.

[70]. Coskun, O.; Kanter, M.; Korkmaz, A.; Oter, S. Pharmacol. Res. 2005, 51, 117-123.

[71]. Mohammadi, J.; Naik, P. R. Turk. J. Biol. 2012, 36, 211-216. 